\title{
Minimizing Net Carbon Dioxide Emissions by Oxidative Co-Pyrolysis of Coal / Biomass Blends
}

Technical Progress

Report for the Period: $\quad$ October 1, 2000 - March 31, 2001.

Principal authors: $\quad$ Robert Hurt, Brown University

Todd Lang, Brown University

Report Issue Date: June 25, 2001

DOE Award Number: $\quad$ DE-FG26-OONT40827

Submitting Organization(s): Brown University (R. Hurt)

Division of Engineering, Box D

Providence, RI 02912 


\section{Disclaimer}

This report was prepared as an account of work sponsored by an agency of the United States Government. Neither the United States Government nor any agency thereof, nor any of their employees, makes any warranty, express of implied, or assumes any legal liability or responsibility for the accuracy, completeness, or usefulness of any information, apparatus, product, or process disclosed, or represents that its use would not infringe privately owned rights. Reference herein to any specific commercial product, process, or service by trade name, trademark, manufacturer, or otherwise does not necessarily constitute or imply its endorsement, recommendation, or favoring by the United States Government or any agency thereof. The views and opinions of authors expressed herein do not necessarily state or reflect those of the United States Government or any agency thereof. 


\begin{abstract}
Solid fuels vary significantly with respect to the amount of $\mathrm{CO}_{2}$ directly produced per unit heating value. Elemental carbon is notably worse than other solid fuels in this regard, and since carbon (char) is an intermediate product of the combustion of almost all solid fuels, there is an opportunity to reduce specific $\mathrm{CO}_{2}$ emissions by reconfiguring processes to avoid char combustion wholly or in part. The primary goal of this one-year Innovative Concepts project is to make a fundamental thermodynamic assessment of three modes of solid fuel use: (1) combustion, (2) carbonization, and (3) oxidative pyrolysis, for a wide range of coal and alternative solid fuels. This period a large set of thermodynamic calculations were carried out to assess the potential of the three processes. The results show that the net carbon dioxide emissions and the relative ranking of the different processes depends greatly on the particular baseline fossil fuel being displaced by the new technology. As an example, in a baseline natural gas environment, it is thermodynamically more advantageous to carbonize biomass than to combust it, and even more advantageous to oxidatively pyrolyze the biomass.
\end{abstract}




\section{TABLE OF CONTENTS}

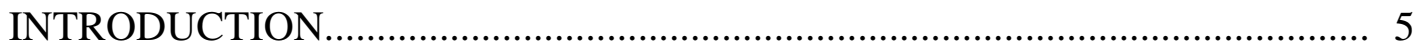

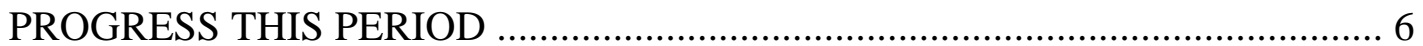

Results and Discussion ....................................................................... 6

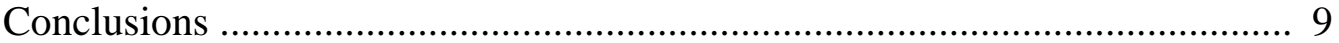

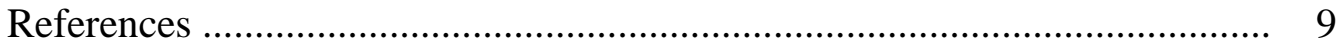




\section{INTRODUCTION}

Increasing concern over global climate change is motivating a technical reassessment of the current modes of fuel use in the United States. Solid fuels vary significantly with respect to the amount of $\mathrm{CO}_{2}$ directly produced per unit heating value, due to the combined effects of varying enthalpy and carbon weight percentages. Elemental carbon is notably worse than other solid fuels in this regard, and since carbon (char) is an intermediate product of the combustion of almost all solid fuels, there is an opportunity to reduce specific $\mathrm{CO}_{2}$ emissions by reconfiguring processes to avoid char combustion wholly or in part. The intentional partial combustion of coal has several practical disadvantages, however. Partial combustion creates large quantities of unburned carbon, which renders the fly ash unsuitable as an admixture in concrete, where it serves as a cement substitute [Freeman et al., 1997]. Avoiding cement manufacture reduces net $\mathrm{CO}_{2}$ emissions in two ways: it reduces fuel use in the kiln and it avoids $\mathrm{CO}_{2}$ emissions associated with limestone calcination. Intentional partial combustion of coal can also cause problems with electrostatic precipitator operation due to high-carbon fly ash. An intriguing alternative is the oxidative pyrolysis of biomass carried out in conjunction with traditional coal combustion, as described below.

Large quantities of $\mathrm{CO}_{2}$ (388 Gigatons / yr ) are released each year due to the natural respiration and decay of biomass in forests, agricultural applications, and landfills [Klass, 1998]. Combustion of waste biomass fuels (e.g. wood, paper, agricultural residues) leads to decreases in real $\mathrm{CO}_{2}$ emission, because the alternative is coal combustion plus natural biological degradation of the biomass carbon to $\mathrm{CO}_{2}$. Further, if biomass degradation is partially anaerobic, some of the carbon is converted to $\mathrm{CH}_{4}$ (an even more potent greenhouse gas) and there is even more motivation to burn biomass fuels and avoid natural decay. The co-firing of biomass and coal in existing coalfired boilers has received much attention as a promising option for reducing net $\mathrm{CO}_{2}$ emissions. Co-firing combines the advantages of biomass (reduced net $\mathrm{CO}_{2}$ emissions) with the advantages of coal (stable operation, high efficiency, and favorable economics of large coal-fired power plants). The single most important hurdle to expanded use of biomass in co-firing is the distributed nature of the source and its low volumetric energy density, making handling, processing, and transport to centralized power generating facilities expensive. The arguments for partial combustion can also be applied to biomass, so $\mathrm{CO} 2$ offsets from cofiring can be further enhanced by leaving a portion of the biomass char unburned. such an oxidative pyrolysis process may be especially advantageous if it can be carried out in a way the does not perturb the coal combustion subprocesses with their high efficiency, well-developed environmental controls, and byproduct utilization.

Other authors have proposed the straight carbonization of biomass residues to sequester carbon in its stable elemental form [Bilger, 1999]. Although this process does not produce heat, it the associated carbon storage credits can have a significant positive impact on $\mathrm{CO}_{2}$ emissions, while not necessarily requiring transportation of the voluminous biomass to large, central power stations. The primary goal of this one-year Innovative Concepts project is to make a fundamental thermodynamic assessment of these various modes of solid fuel use. 


\section{PROGRESS THIS PERIOD}

In the first six months of this Innovative Concepts project, we have carried out thermodynamic calculations on a large set of traditional and alternative fuels to establish the ultimate constraints on the $\mathrm{CO}_{2}$ emissions during (a) combustion, (b) carbonization (with no heat export), (c) oxidative pyrolysis. The full set of calculations were done for a matrix of cases considering:

- wet vs. dry utilization

- ASTM volatile yields vs. true chemical equilibrium in the pyrolysis step

- incremental utilization of alternative fuels in one of two traditional fossil-fuel environments:

- one in which baseline energy is provided by combustion of high-volatile bituminous coal, - one based on natural gas

\section{Results and Discussion}

The calculations show very clear trends with fuel type, process type (combustion / carbonization / oxypyrolysis), and with the baseline fossil-fuel environment in which the alternate fuel utilization takes place. Some examples of the calculations done to date are shown in Figs. 1-3.

Figure 1 shows the direct specific carbon dioxide emission from combustion of various fuels. These "direct" emissions are those produced by the combustion process itself, without regard for auxiliary effects on the environment, such as credits for re-grown or the avoidance of biochemical decay, etc. in alternate scenarios. Figure 1 clearly shows that the direct emissions vary significantly among fuels, and that elemental carbon is the worst fuel for specific $\mathrm{CO}_{2}$ emissions.

Figure 2 considers oxidative pyrolysis for each of the fuels, and compares the direct carbon dioxide emissions to those from conventional combustion. As expected, in all cases oxidative pyrolysis produces less carbon dioxide per MJ of lower heating value than does combustion - a direct logical consequence of the fact that elemental carbon (the char intermediate) is the worst fuel in this regard. Stopping combustion at the char oxidation stage always leads to some reduction in carbon dioxide emissions per unit heating value. The magnitude of the effect various with fuel however. An especially large effect is observed for low-volatile coals, due to their hydrogen-rich and oxygendeficient volatile matter. Oxidative pyrolysis of low volatile coals is not as attractive as Fig. 2 might suggest, however, since it would require the processing of very large amounts of material, 80-90\% of which must be stored as carbon. A more useful index must be defined that is expresses the total carbon dioxide impact per $\mathrm{kg}$ of fuel processed.

In addition to modifying the index per $\mathrm{kg}$ of fuel, we must also modify the index to account for other effects of the proposed process. For example, burning agricultural wastes produces large amounts of carbon dioxide per unit heating value (see Fig. 2), but if the alternative is decay in the field, this carbon dioxide would have been produced anyway with no useful energy production. Figure 3 shows an example of a calculation of net $\mathrm{CO} 2$ emission per $\mathrm{kg}$ of fuel processed, by (a) combustion, (b) oxidative pyrolysis, and (c) straight carbonization. 


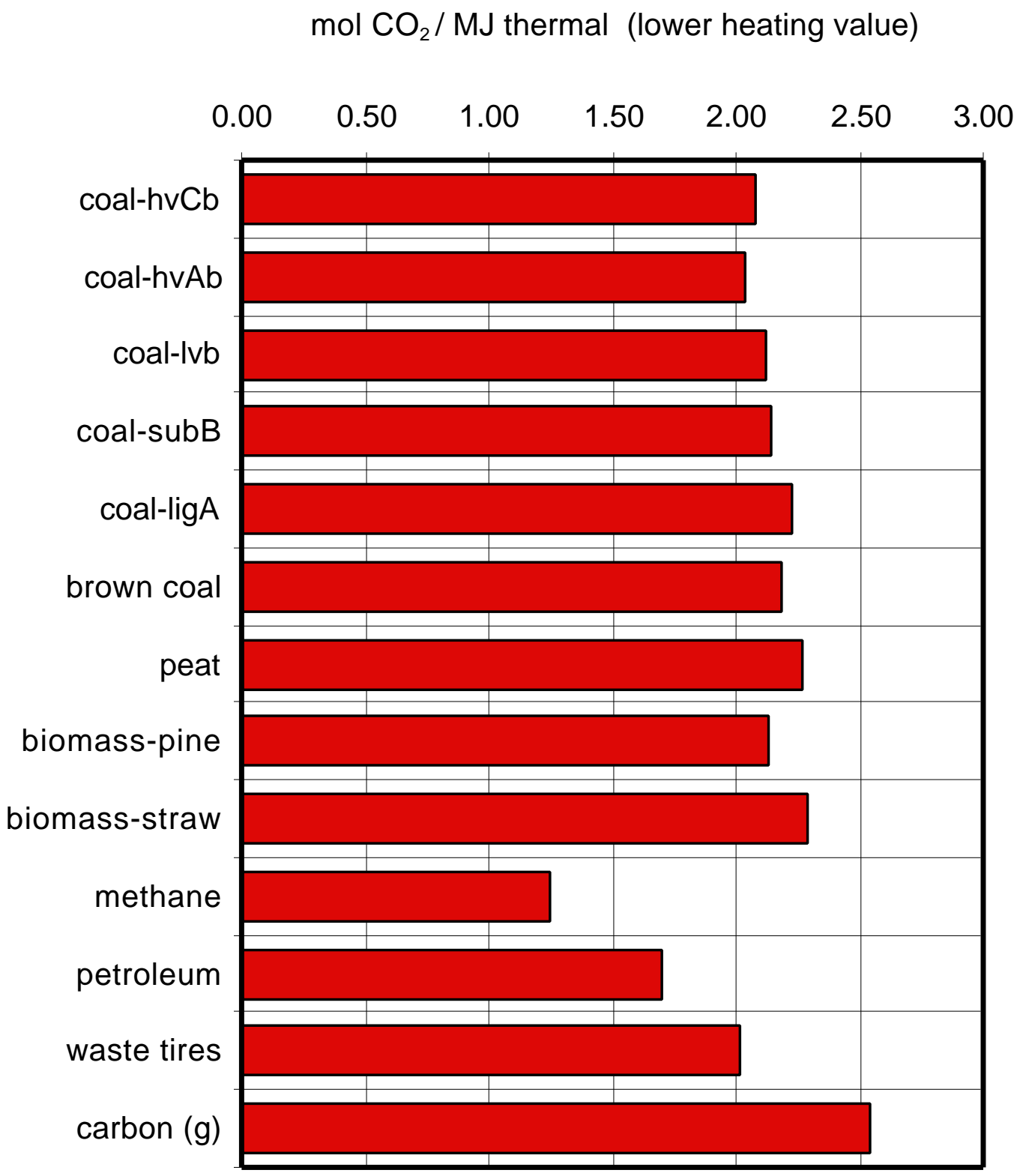

Figure 1. Direct specific carbon dioxide emissions from the combustion of various solid fuels (with the non-solid fuels methane and petroleum shown for reference.) 
口 combustion $\square$ oxidative pyrolysis

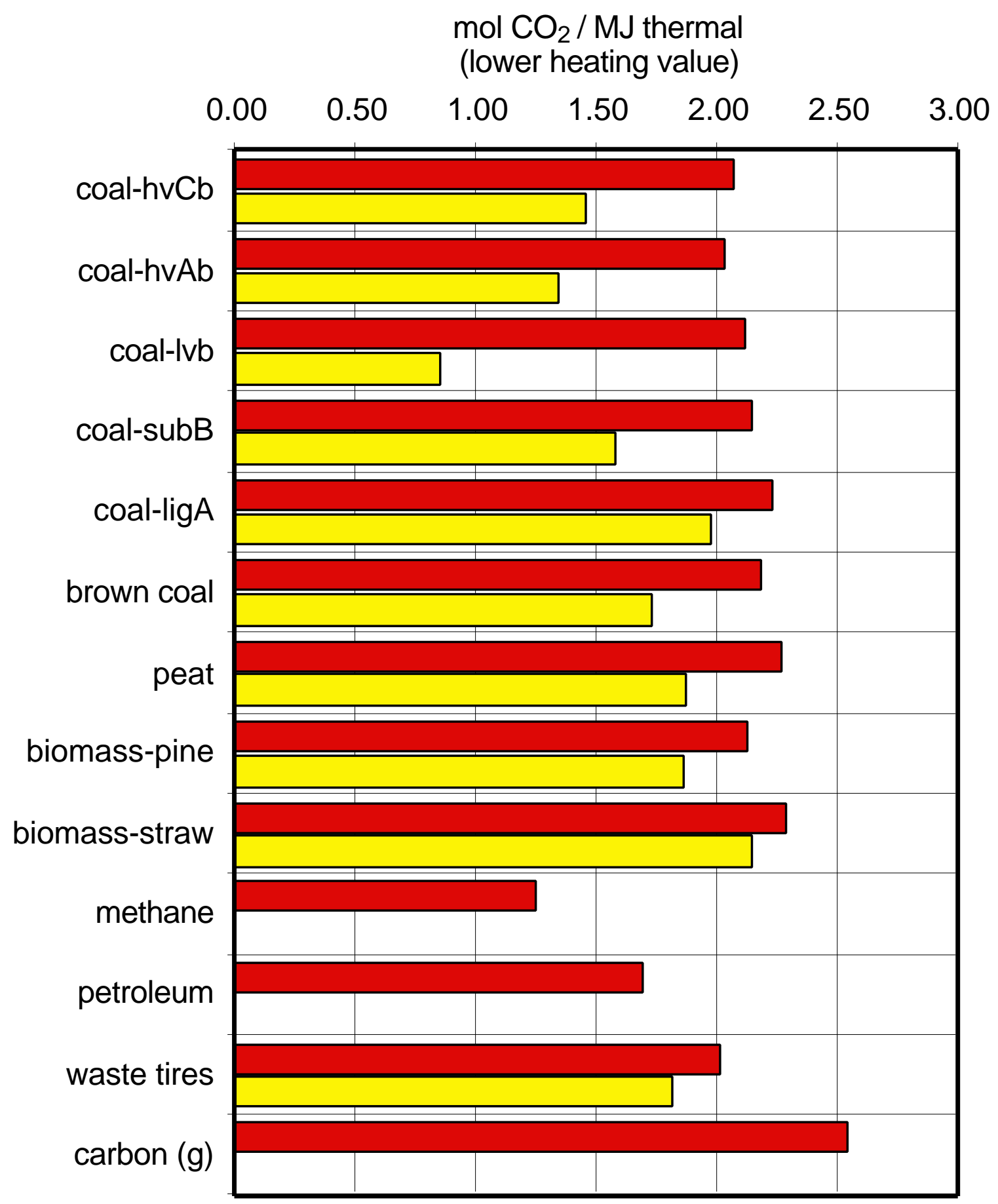

Figure 2. Direct specific carbon dioxide emissions for combustion vs. oxidative pyrolysis. 
Of particular interest are the calculations involving biomass. In a baseline coal environment (not shown), biomass cofiring is much more beneficial than straight carbonization. Oxidative pyrolysis gives slightly higher $\mathrm{CO}_{2}$ offsets, but likely not enough to warrant the additional process complexity. In a baseline natural gas environment (Fig. 3), where the alternative fuel use displaces gas, the two options involving elemental carbon storage (carbonization and oxypyrolysis) begin to look more attractive. On a thermal basis, simple carbonization provides $80 \%$ of the $\mathrm{CO}_{2}$ offset achievable by biomass combustion, while oxidative pyrolysis produces a $40 \%$ larger $\mathrm{CO}_{2}$ offset than biomass combustion. The effects are largest when the energy product is electricity. In a baseline gas environment, accounting for the higher efficiency of gas-fired plants relative to dedicated biomass-only systems, both straight carbonization and oxidative pyrolysis give much larger $\mathrm{CO}_{2}$ offsets than traditional biomass carbonization - a very interesting result.

\section{Conclusions}

The project has generated a number of ideas, but firm technical conclusions will be drawn only after further examination of the results in the second project period. A publication on this topic is tentatively planned, with probable submission at the end of the summer of 2001, at about the same time as final report preparation.

\section{References}

Bilger, R.W. "The Future for Energy from Combustion of Fossil Fuels", Fifth International Conference on Technologies and Combustion for a Clean Environment, Lisbon, Portugal, pp. 617623, 1999.

Freeman, E., Gao, Y.M., Hurt, R.H., Suuberg, E.S. "Interactions of Carbon-Containing Fly Ash with Commercial Air Entraining Agents for Concrete," Fuel, 76 (8) 761-765 (1997).

Klass, D.L., Biomass for Renewable Energy, Fuels, and Chemicals, Academic Press, San Diego, 1998. 


\section{Baseline Environment: Natural Gas}

$\square$ combustion, $\mathrm{db}$

oxidative pyrolysis, $\mathrm{db}$

carbonization, db

$\Delta \mathrm{mol} \mathrm{CO}_{2} / \mathrm{kg}$ fuel processed

$\begin{array}{llllll}-40.0 & -20.0 & 0.0 & 20.0 & 40.0 & 60.0\end{array}$

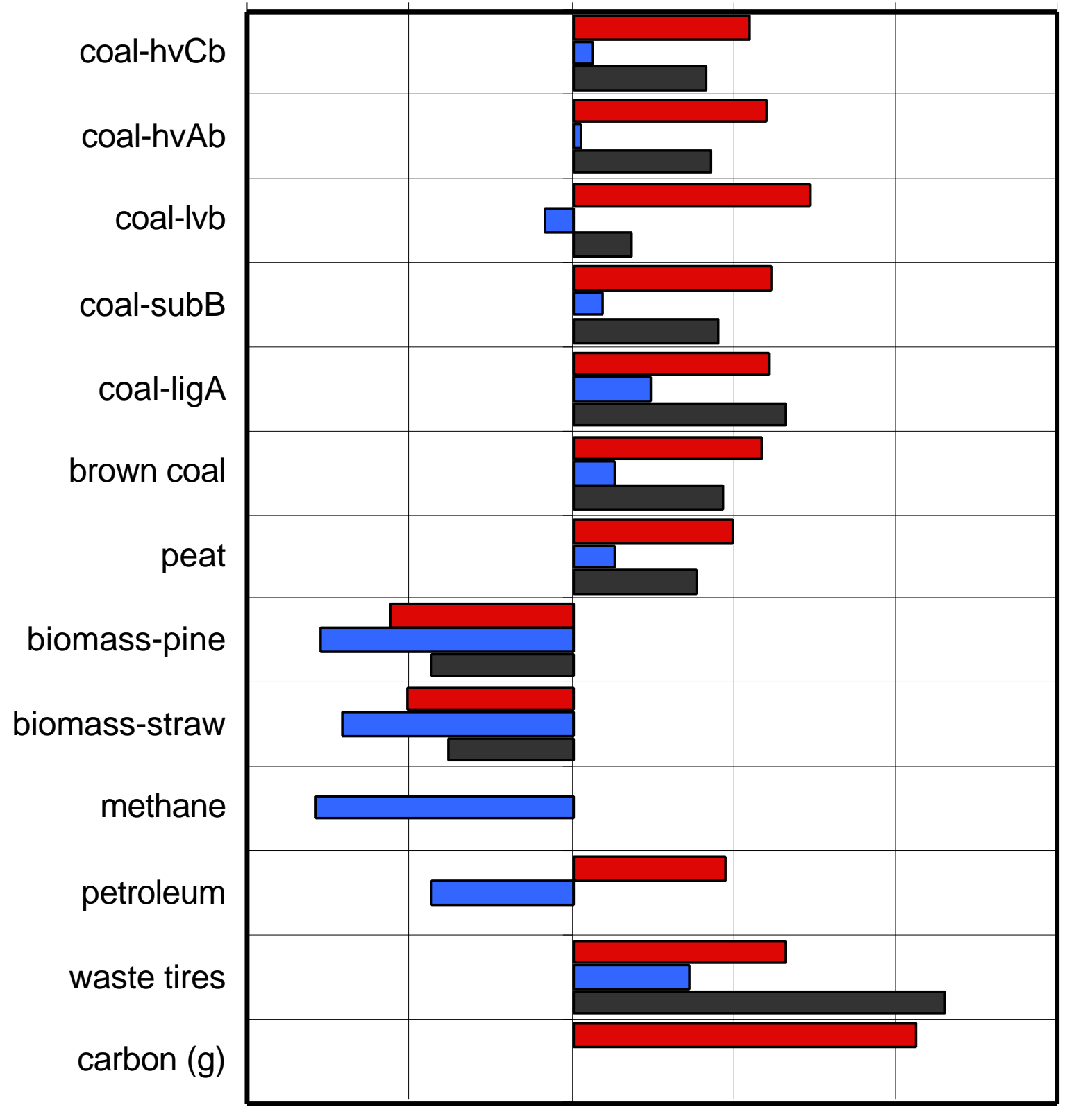

Figure 3. Net carbon dioxide emissions per unit mass of various solids processed, considering three separate technologies: combustion, carbonization, and oxypyrolysis. 